\title{
Las ciudades de tamaño mediano y óptimo en Andalucía
}

Antonio Bonet Correa. Catedrático Emérito de Historia del Arte

\author{
Andalucía cuenta con \\ un conjunto \\ demográfico y urbano \\ de clara personalidad \\ cultural concentrado en \\ "agrociudades" \\ y "ciudades-aldea"
}

El tema de la dimensión y la categoría de las ciudades ha sido siempre objeto de reflexión por parte de quienes se han interesado por los fenómenos urbanos. A lo largo de los siglos, tanto los filósofos como los legisladores, los geógrafos, los historiadores, los sociólogos y los urbanistas han querido encontrar la clave que explica el crecimiento de las aglomeraciones humanas, las cuales a partir de una aldea pueden acabar convirtiéndose en una megápolis o ciudad tentacular. También ha sido su deliberado propósito el determinar cuál, en su opinión, es la dimensión más idónea de su perímetro y la más óptima cifra de número de habitantes para la que se pueda considerar ciudad ideal. A la vez es de tener en cuenta que, junto al campo de lo teórico y lo especulativo, desde la Antigüedad hasta nuestros días, en la práctica urbanística en todo tiempo ha existido una política de creación de ciudades que, por sus dimensiones, se han juzgado perfectas o modélicas de la ciudad mediana y de descongestión de las grandes metrópolis. Tal fue el caso de las colonias griegas en el Mediterráneo antiguo o el de las ciudades-satélites británicas, proyectadas en el siglo XX después de la última guerra mundial.
En el terreno teórico acerca de las dimensiones ideales para la ciudad, recordemos el pensamiento conservador y reduccionista de Platón, la utopía de Tomás Moro, los principios sobre la demografía de Giovanni Botero, precursor de Malthus, las propuestas igualitarias de los socialistas utópicos del siglo XIX o los proyectos idílicos de ciudad-jardín formulados por Sir Ebenezer Howard. A las opiniones de todos ellos y de muchos de sus seguidores, hay que añadir las de los contrarios a lo urbano. Frente a la idea de la ciudad equilibrada, perfecta y armoniosa, se opone la maldición bíblica de la ciudad cainita y "de perdición". Pensadores, filósofos y poetas como Rousseau, Nietzsche, Verhaeren o Heidegger consideraban que las grandes ciudades absorbían la energía vital del campo que las rodeaba, además de ser caóticas y depravadas.

Desde la perspectiva de la historia del urbanismo se puede concluir que el nacimiento de las ciudades consiste en un proceso progresivo de cambio de los modos de vida rural hacia los urbanos. Las grandes aglomeraciones humanas que acaban convirtiéndose en enormes metrópolis no sólo engullen su entorno más inmediato sino que, por medio de la emigración que está atraída por ellas, pueden perjudicar no sólo a las ciudades medianas más cercanas 


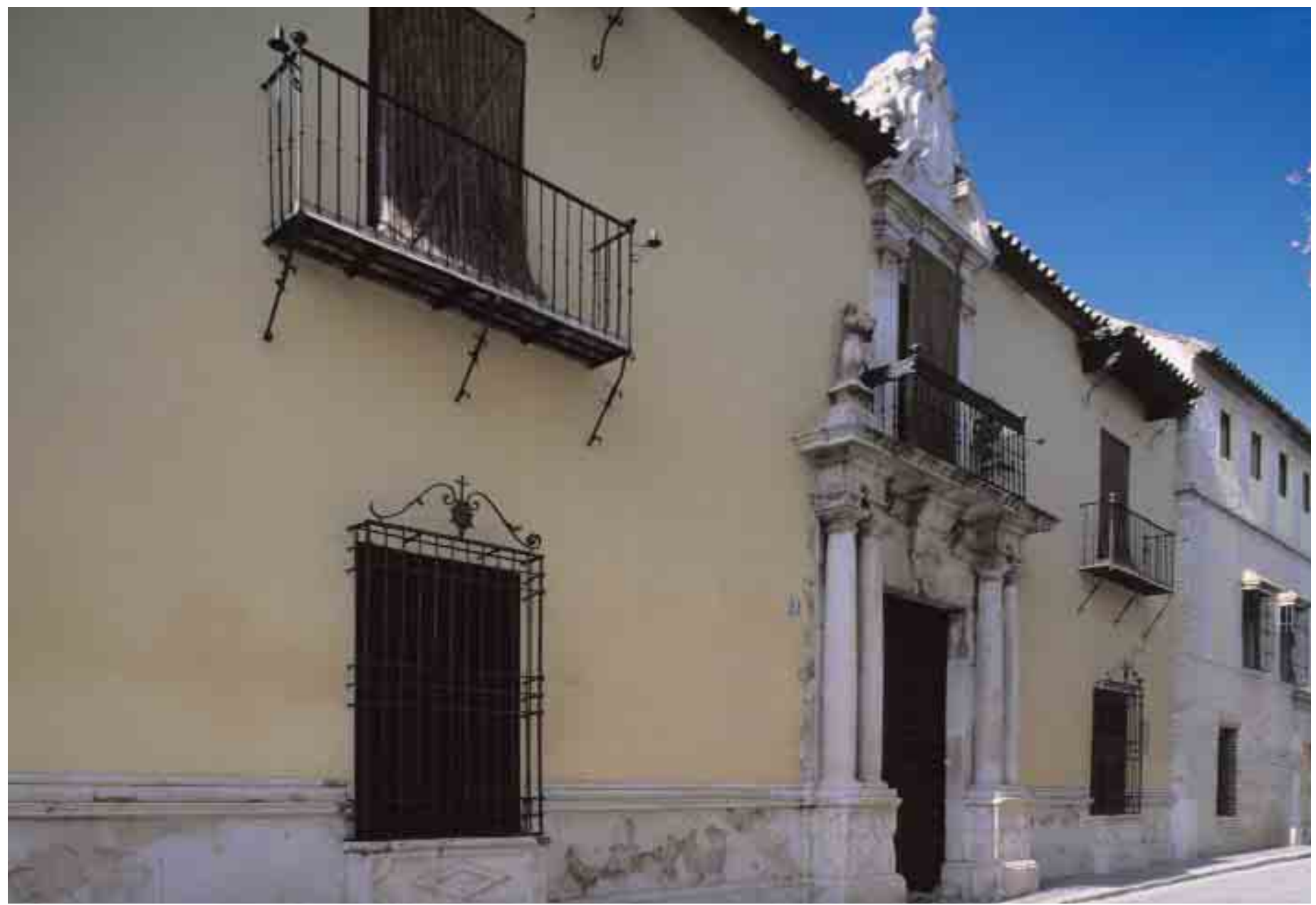




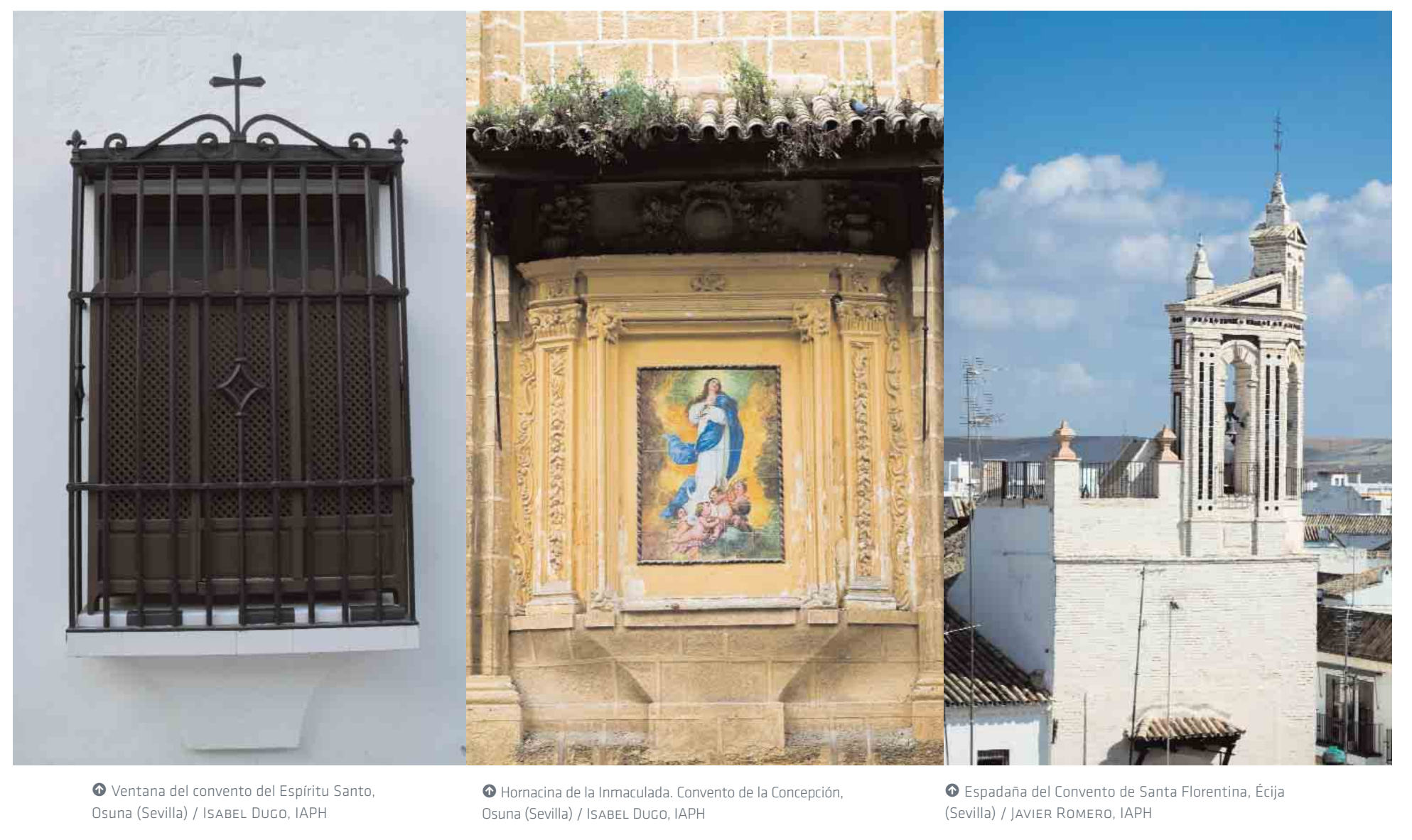

sino incluso a las muy lejanas. En un discurso titulado Las ciudades medias, pronunciado en la apertura de curso de 1968 en la Universidad de Granada, el catedrático de la Facultad de Ciencias Políticas, Económicas y Comerciales, Alfonso García Barbancho, afirmaba que Madrid y Barcelona succionaban "como unas grandes ventosas las fuerzas humanas y los potenciales económicos de todo el país" y que eran ciudades que estaban "condenadas a la asfixia". Tras referirse a las poblaciones andaluzas, que según él "a veces tienen una belleza natural que enamoraría a cualquier pintor", acusando la entonces creciente emigración interior, propugnaba para España "la existencia de un plan (que) actúe como moderador y como impulsor de las ciudades medias".

Si traemos aquí al primer plano el debate sobre las dimensiones óptimas de las ciudades es porque sin él un historiador del arte y del urbanismo no puede comprender las peculiaridades de un tipo de población cuyo número es muy abundante en Andalucía. Como es sabido, el extenso territorio de las provincias andaluzas cuenta con un conjunto demográfico y urbano de clara personalidad cultural. De acuerdo con los conceptos geográficos, el enorme acervo andaluz de hábitat concentrado en "agrociudades" y "ciudades-aldea" coincide en gran medida con los de "centros monumentales históricos y artísticos". Junto con la existencia de la dispersión intercalada de haciendas y cortijos, verdaderos núcleos de valor arquitectónico a la altura de los monumentos urbanos, Andalucía constituye un variado cúmulo de poblaciones singulares y de enorme interés estético y monumental. El estudio diacrónico de las ciudades andaluzas es, sin duda, un capítulo esencial de la morfología urbana en el sur de Europa. 


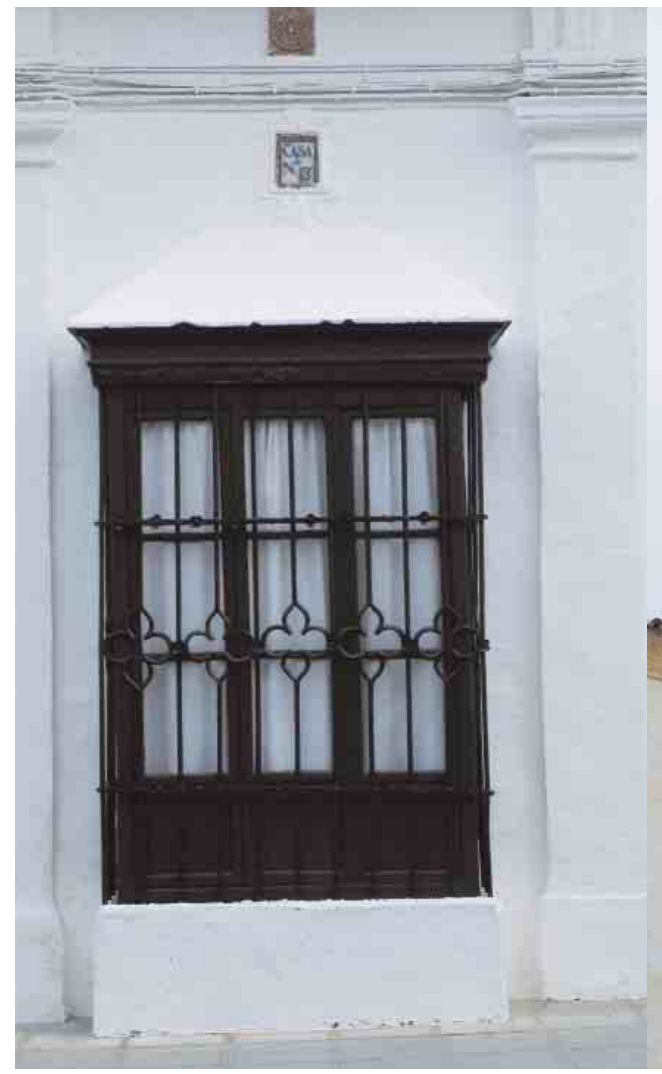

(1) Detalle de ventana en calle San Pedro, Osuna (Sevilla) / ISABEL Dugo, IAPH

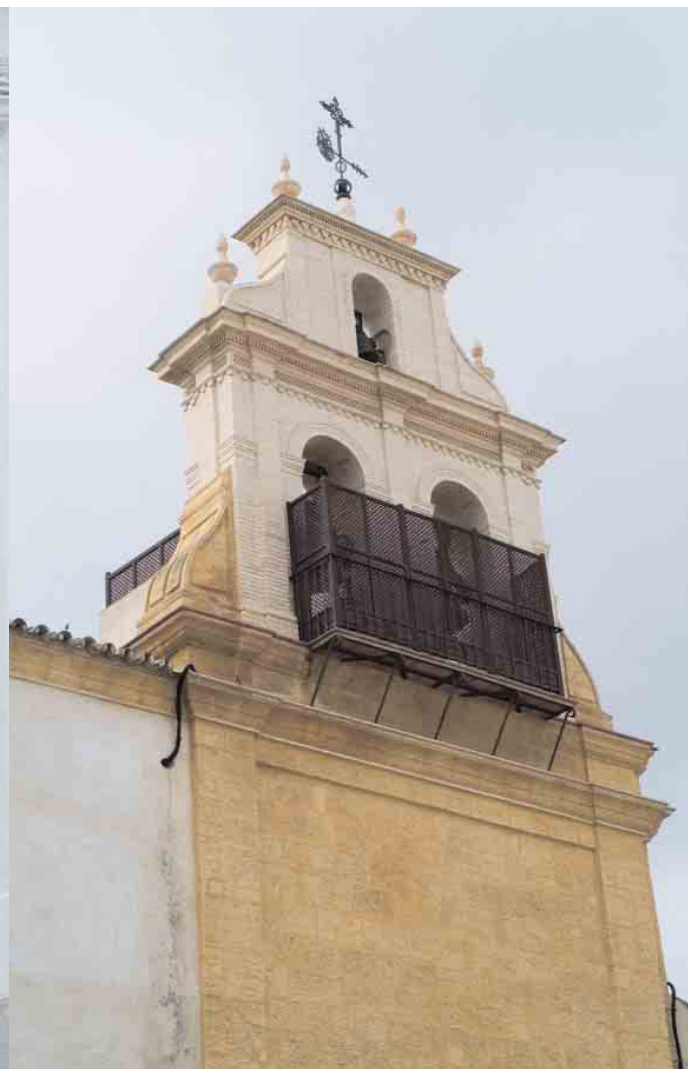

( Espadaña del Convento de San Pedro, Osuna (Sevilla) / ISABEL Dugo, IAPH

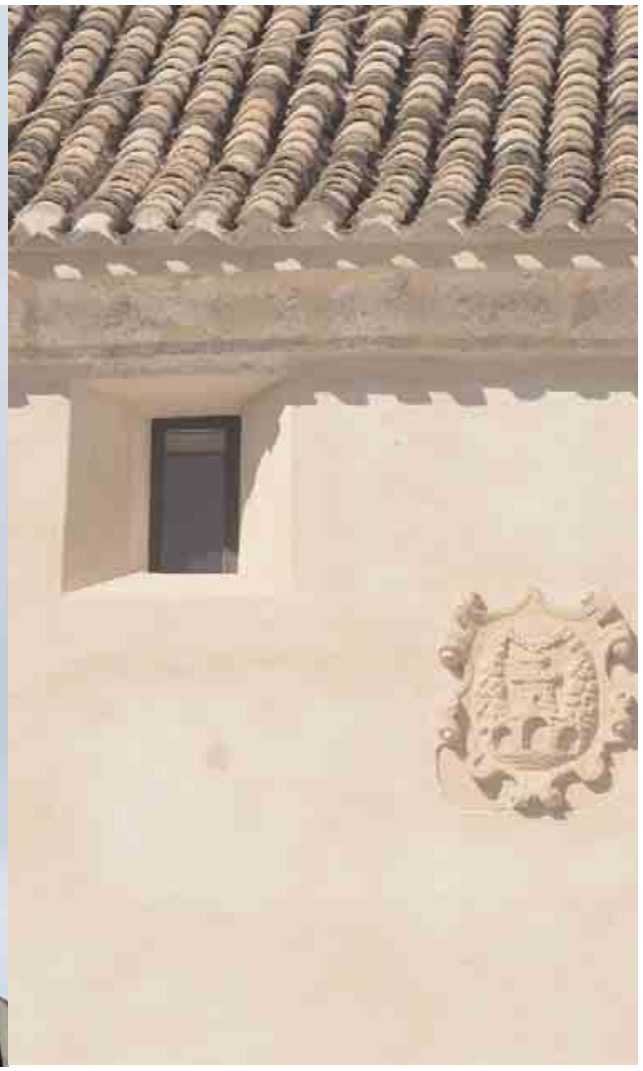

(1) Detalle del Centro de Iniciativas culturales El Pósito, Loja (Granada) / JuAn CARLos CAZALLA, IAPH
Para mayor claridad metodológica conviene distinguir el emplazamiento de las distintas ciudades andaluzas. En primer lugar hay las que se encuentran en las sierras y altiplanos interiores y las que, construidas sobre una eminencia, cuentan con un castillo más o menos roquero. Su papel, sobre todo en la Edad Media, fue fundamental, tanto en la época de dominio musulmán como en el período posterior de la Reconquista cristiana. En segundo lugar, el grupo quizás más importante es el de las ciudades asentadas en las llanuras con feraces campiñas. A ellas hay que añadir las poblaciones marítimas, con sus puertos y riberas, a veces escarpadas y abruptas.

Desde el punto de vista histórico, es importante señalar que salvo las ciudades de nueva creación como Puerto Real (Cádiz) y Santa Fe (Granada), fundadas por los Reyes Católicos,
Mancha Real y Valdepeñas de Jaén, por Carlos V y Felipe II, La Carolina (Jaén), por Carlos III, o Nueva Carteya (Córdoba), en el siglo XIX, las poblaciones medianas andaluzas hunden sus raíces en los tiempos más remotos. Muchas son de época romana y casi todas han sufrido transformaciones bajo los musulmanes y después los cristianos. Muchas son señoriales y otras de realengo. Las ciudades ducales como Osuna, por citar un ejemplo relevante, son un compendio de los más altos valores arquitectónicos y artísticos. Ninguna carece de los elementos necesarios que caracterizan un acabado conjunto histórico propio de una sociedad estamental y agraria. A los palacios señoriales, las iglesias y los monasterios masculinos y femeninos, hay que añadir los edificios administrativos, pósitos, cillas, fuentes y demás servicios públicos. En la arquitectura religiosa se encuentran, además de las ermi- 


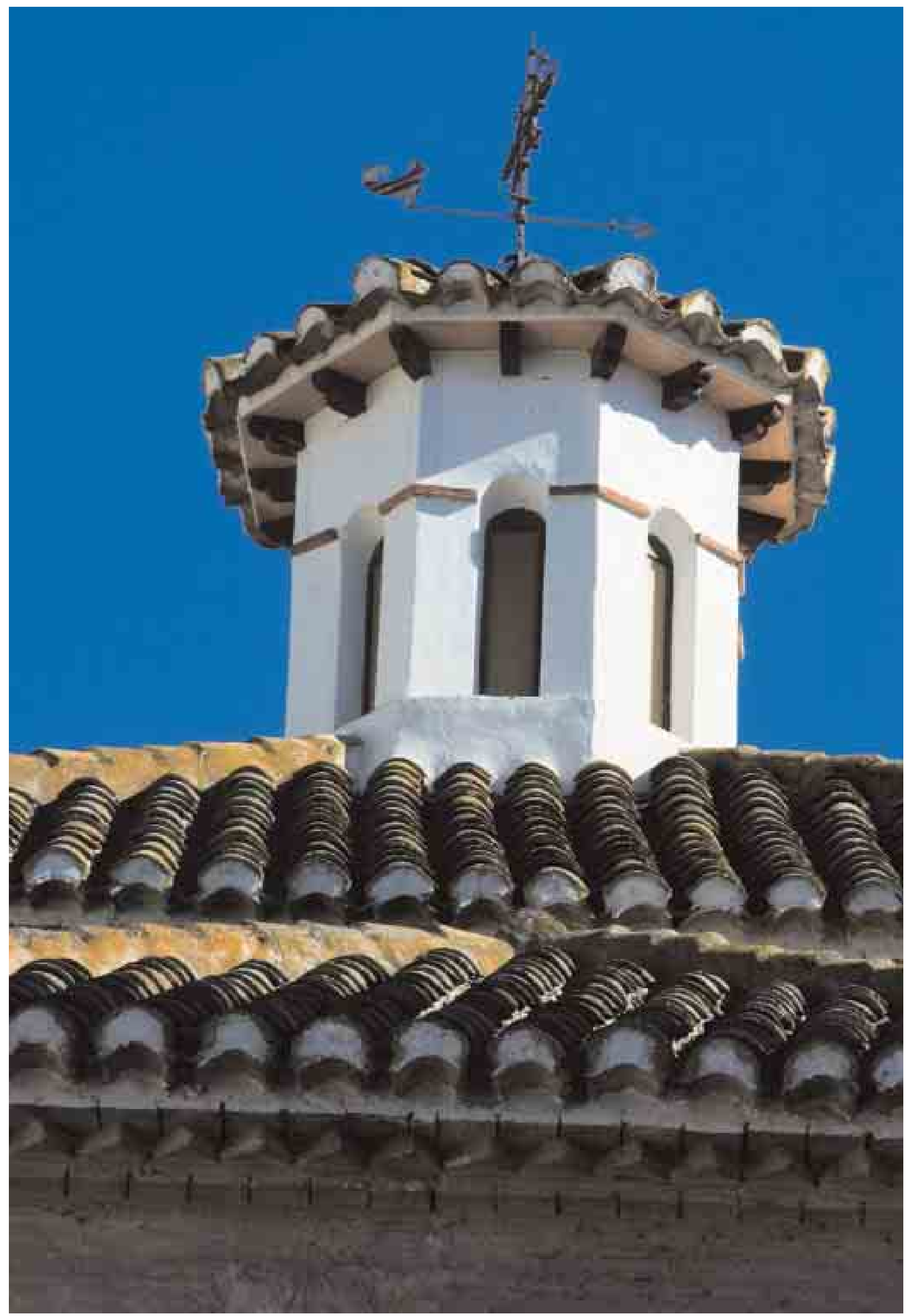

(1) Linterna de la Ermita de Nuestro Padre Jesús Nazareno de Loja (Granada) / JuAN CARLos CAZALLA, IAPH 
tas, capillas posas para las procesiones, cruces, triunfos, hornacinas e imágenes en las esquinas de las fachadas de los edificios y en las encrucijadas de las calles y plazuelas.

Elementos esenciales en las ciudades son las esbeltas y altas torres de los templos. Junto con las espadañas, los miradores con celosías de los conventos de monjas o los balcones de las mansiones nobles, forman, con la variedad de estilos y en especial de la época barroca, la faz de la ciudad, que en Andalucía cambia de comarca en comarca pero que siempre mantiene denominadores comunes. El sincretismo artístico mudejarismo-barroco-rococó es el dominante, aunque existen focos renacentistas tan llamativos y unitarios de gran calidad como Baeza o Úbeda. Indudablemente, con sus distintas variantes e inflexiones, Andalucía es una tierra eminentemente barroca. No cabe duda de que, en el siglo XVIII, con su prosperidad económica, renovó gran número de edificios. También de que el terremoto de Lisboa en 1755, con grandes repercusiones en Andalucía occidental, hizo que se reconstruyesen y renovasen en barroco la mayoría de las fábricas de sus edificios.

Jürgens, en su célebre libro sobre las ciudades españolas, al hablar de la morfología urbana andaluza, señala cómo los hastiales de las casas, al sobresalir de las alineaciones de las calles, subrayan las esquinas de los edificios, creando unos efectos escenográficos que realzan la arquitectura civil aunque ésta sea en sí misma muchas veces modesta. Deambular por una ciudad, de calles estrechas, rectas o ligeramente curvadas, de plazas y encrucijadas pintorescas, con casas de rejas y fachadas blancas o de colores suaves, palacios con portadas pétreas y blasonadas depara al viandante no sólo sorpresas visuales sino gratas sensaciones, nacidas de la armonía que muestra la perfecta adecuación del caserío acorde con la mesurada dimensión de la población.

Una de las mayores satisfacciones de la que todavía se puede disfrutar en Andalucía es la de gozar desde la Iontananza del perfil de muchas de sus ciudades. En especial las aglomeraciones medianas conservan vistas panorámicas aún intactas. En las ciudades de Ilanuras de aluvión o de suaves lomas, el efecto es magnífico. También resulta de extraordinaria belleza cuando la ciudad aparece recostada sobra una cima de montaña. Ejemplos como Palma del Río, Écija, Lebrija, Carmona o Estepa pueden ser citados por sus torres y campanarios, que sirven de puntos de referencia, de verdaderos hitos plásticos. En el caso de Antequera, la torre que domina las espadañas circundantes es como el epicentro urbano. Importantes son también los espolones y paseos que al borde de un tajo como los de Ronda, Priego de Córdoba o Baeza hacen que el viandante asomado a sus majestuosos balcones goce de una vista panorámica de hermosísimos paisajes. Es la operación contraria a la de ver la ciudad en su faz exterior. Desde el interior de la trama urbana contempla la inmensidad de los campos y las montañas lejanas.

Difícil resulta resumir en unas cuantas páginas la variedad y riqueza de las ciudades medianas andaluzas. Arcos y Vejer, Moguer, Jerez de la Frontera o El Puerto de Santa María, en Andalucía occidental y Alcalá la Real, Loja, Guadix, Vélez Blanco y Vélez Rubio, Cuevas de Almanzora o Mojácar en Andalucía oriental merecerían ser analizadas como poblaciones con sus particulares características. Otro tanto diríamos de Quesada que, a manera de ciudad metafísico-surrealista, retrató el pintor Zabaleta, o Linares, industrial y decimonónica que, con la muerte de Manolete, pasó a ser conocida en todo el ámbito hispánico. Sin duda, al igual que los viajeros románticos, el actual turista ilustrado sabe hoy apreciar no sólo la belleza de sus monumentos y de su morfología urbana, sino también, de acuerdo con la teoría de la ciudad bien dimensionada y bien trazada, la bondad de su tamaño y la disponibilidad para la vida de sus habitantes. El sueño de los filósofos idealistas parece haberse cumplido dentro del acotado perímetro urbano de las ciudades medianas de Andalucía. 


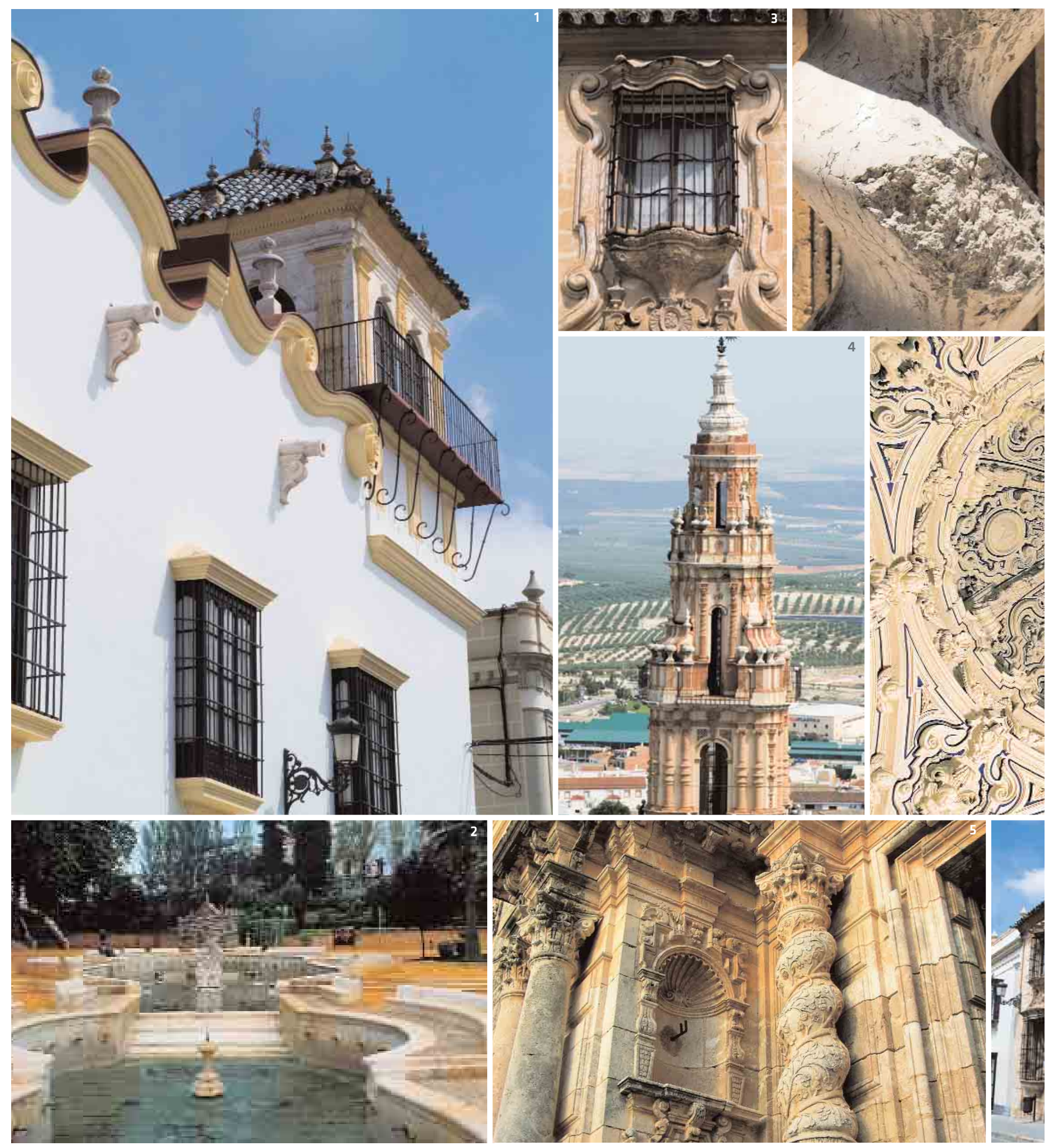

